\title{
Impact Hazard Assessment of Mine Roadway Excavation in Fault and Karst Erosion Area
}

\author{
Zenghui Zhao \\ State Key Laboratory of Mine Disaster \\ Prevention and Control \\ Shandong University of Science and \\ Technology \\ Qingdao, China \\ tgzyzzh@163.com
}

\author{
Xiaojie Gao \\ State Key Laboratory of Mine Disaster \\ Prevention and Control \\ Shandong University of Science and \\ Technology \\ Qingdao, China \\ 15005425712@163.com
}

\author{
Qing Ma \\ State Key Laboratory of Mine Disaster \\ Prevention and Control \\ Shandong University of Science and \\ Technology \\ Qingdao, China \\ 15764250774@163.com
}

\begin{abstract}
The evaluation method of impact hazard during the recovery of the working face is mature, but the evaluation indexes or factors considered by these methods are difficult to apply to the risk analysis of roadway excavation in the areas with faults and karst. Therefore, the fuzzy comprehensive evaluation method is applied to the evaluation of the impact hazard during the excavation of the west track lane in a certain mine. At first, using FLAC ${ }^{3 \mathrm{D}}$ to analyze the impact hazard of roadway excavation in fault and karst erosion area. Then, the fuzzy comprehensive evaluation method is used to establish the risk evaluation index system by considering geological factors and mining technical conditions, and the membership functions and the fuzzy matrix are determined. Then, the weight of each index is identified and the impact risk level is evaluated. The results show that the West track Lane has no impact hazard, which is consistent with the measured results of drilling cuttings method. The above conclusion shows that the fuzzy comprehensive evaluation method can be used to evaluate the impact hazard during roadway excavation.
\end{abstract}

Keywords-roadway excavation, FLAC ${ }^{3 D}, \quad$ fuzzy comprehensive evaluation method, impact hazard assessment

\section{INTRODUCTION}

Rock burst is one of the most typical coal and rock dynamic disasters in coal mining. It mainly refers to the sudden destruction of coal and rock in underground coal mines. Due to the sudden release of energy in the coal and rock mass, the damage of the support and equipment, the casualties, the collapse of some roadways and other engineering disasters are caused. At the same time, rock burst may cause other mine disasters, such as coal and gas outburst, fire and flood, ventilation obstruction [1-3]. The rock burst has the characteristics of suddenness, instantaneous vibration and huge destructiveness. This kind of disaster usually has no obvious macroscopic omen and it is difficult to accurately forecast the time, place and intensity. Rock burst is accompanied by a huge sound and strong shock, which usually causing casualties and huge economic loss. Therefore, it has important sense to carry out the early warning of impact hazard in mine roadway [4-6].

At present, many scholars at home and abroad have done lots of research and analysis on the risk of rock burst in coal mine, and put forward a variety of evaluation methods of impact hazard from different angles. References [7-9] reported the methods of numerical simulation and laboratory test to analyze the failure characteristics and mechanical properties of the coal-rock combinations, and studied the mechanism of rock burst in mine. References [10-11] established the impact hazard assessment model based on the quantitative theory, and put forward the criterion of the impact hazard discrimination. Based on the analysis of impact hazard, the prediction and prevention system of the rock burst have been constructed. References [12-13] studied the impact hazard by using the geological dynamic zoning method, which considering the fracture structure and the characteristics of coal and rock. References [14-15] used the dynamic weighting method to analyze the impact hazard of coal working face mining. References [16-17] studied the impact hazard by using the possibility index method, which considering the distribution of mining stress field and the impact tendency of coal and rock mass. References [18-19] used the comprehensive index method to predict the impact hazard of the coal mining face, and verified the effectiveness of the comprehensive index method. References [20-21] used the fuzzy matter element method to analyze all kinds of mining and geological factors, constructed the evaluation model of the impact hazard, and realized the judgment of the impact hazard.

The above methods play an important role in the safety mining of deep mines and the stability controlling of roadway. But the evaluation indexes or factors considered by these methods are difficult to apply to the risk analysis of roadway excavation in the areas with faults and karst. Therefore, the fuzzy comprehensive evaluation method is applied to the impact hazard evaluation. The west rail lane is used as an engineering case, and the $F_{L A C}{ }^{3 \mathrm{D}}$ is used to analyze the impact hazard of roadway excavation in fault and karst erosion area. The fuzzy comprehensive evaluation method is used to set up the risk evaluation index system. In addition, comparing the results of calculation with the actual monitoring results, which in order to solve the problem of impact hazard assessment during roadway excavation.

\section{ENGINEERING SITUATION}

The height of the west rail lane in fourth mining area is $680 \mathrm{~m}$ to $-705 \mathrm{~m}$, the length is $1825 \mathrm{~m}$, and the width is $4 \mathrm{~m}$. The heading face is in the NO.3 coal of the lower Permian Shanxi formation, and the overall occurrence pattern of coal seam is east-west trend. The dip angle of coal seam is 5 to 10 degrees, with an average of 8 degrees. It is estimated that the thickness of coal seam is 1.50 to $2.60 \mathrm{~m}$, and the average is $2.00 \mathrm{~m}$. The structure of coal seam is simple and there is no gangue. 
According to the three-dimensional seismic data and the actual geological data, there is no large and medium-sized fault during roadway excavation. The FD93 fault is expected to be exposed in the middle of the roadway. The fault throw is $0-5 \mathrm{~m}$, which is a normal fault of descending south. In addition, there are FD78 and FD79 faults near the west rail lane at the end of the magmatic rock erosion area, and the fault throw are $0-5 \mathrm{~m}$ and $0-9 \mathrm{~m}$ respectively. It is predicted that the karst erosion area will be revealed during the excavation of the working face. Magmatic rocks are gray to greyish green, crystalloid and massive, with irregular fractures, containing pyroxene crystal spots, pore structure and medium hardness. Magmatic rocks intruded in the form of a rock bed, and the influence range is about $550 \mathrm{~m}$. According to geological data and actual conditions, there is no subsidence column geological structure in the mine area. The preconceived geological section of the West track Lane is shown in Fig. 1.

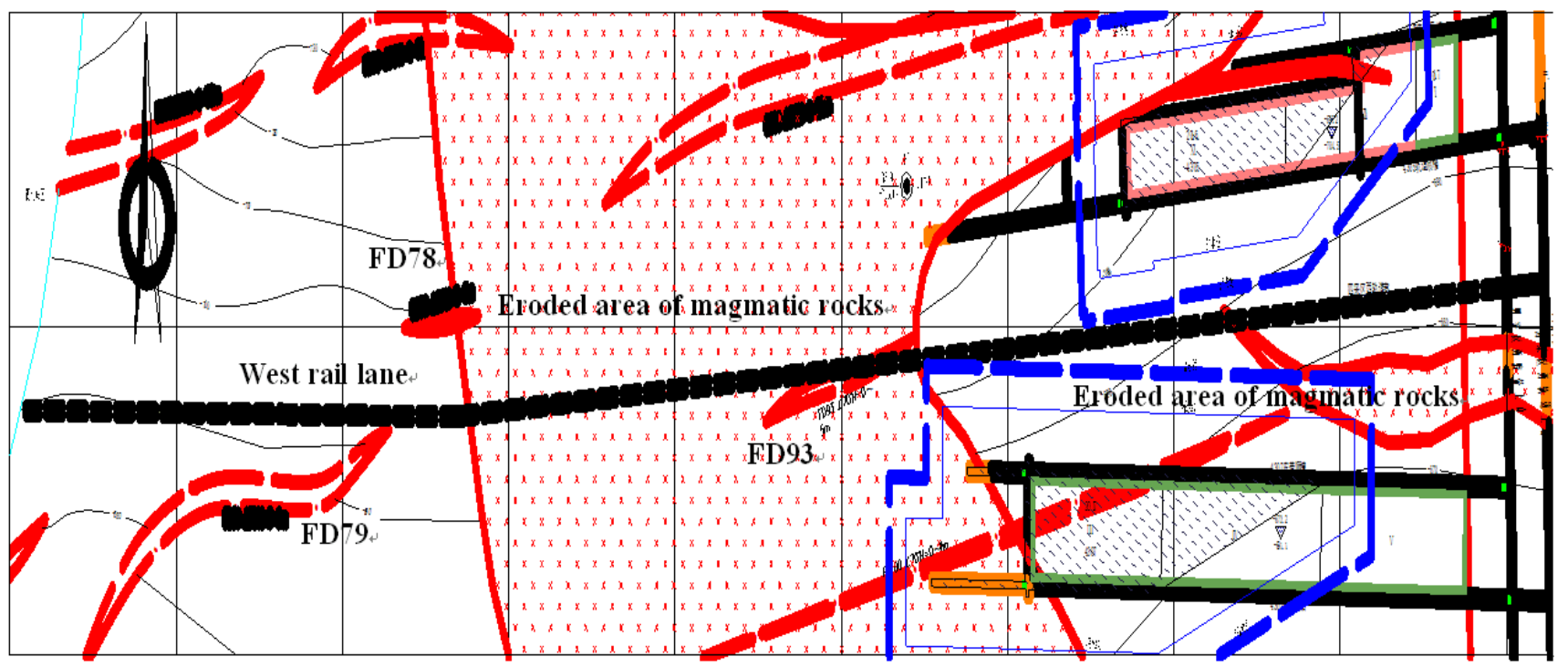

Fig. 1. The preconceived geological section of the west track lane in the fourth mining area

III. STRESS DISTRIBUTION AND PLASTIC ZONE EVOLUTION OF SURROUNDING ROCK IN FAULT AND KARST EROSION AREA DURING ROADWAY EXCAVATION

\section{A. Stress distribution and failure characteristics of surrounding rock during roadway crossing the karst erosion area}

\section{Calculating model}

The model is built by FLAC ${ }^{3 \mathrm{D}}$ software. The size of the model is $100 \mathrm{~m} \times 120 \mathrm{~m} \times 100 \mathrm{~m}$, and the model is divided into ten strata. The Coal seam is in the center of the model, with a depth of 48.5 meters and a thickness of 3 meters. The size of the roadway section is $4 \mathrm{~m} \times 3 \mathrm{~m}$. The end of the roadway is located at the hard rock. The interface between hard rock and soft rock is 80 meters from the initial excavation face. The model is divided into 374463 nodes and 359040 elements. As shown in Fig. 2.

Mohr-Coulomb model is used in this numerical simulation, and the five displacement boundaries are constrained. The pressure of 15MP is applied to the surface of the model, which is used to simulate the pressure of 600 meters stratum. The model is divided into ten strata, and the parameters are shown in Table I.

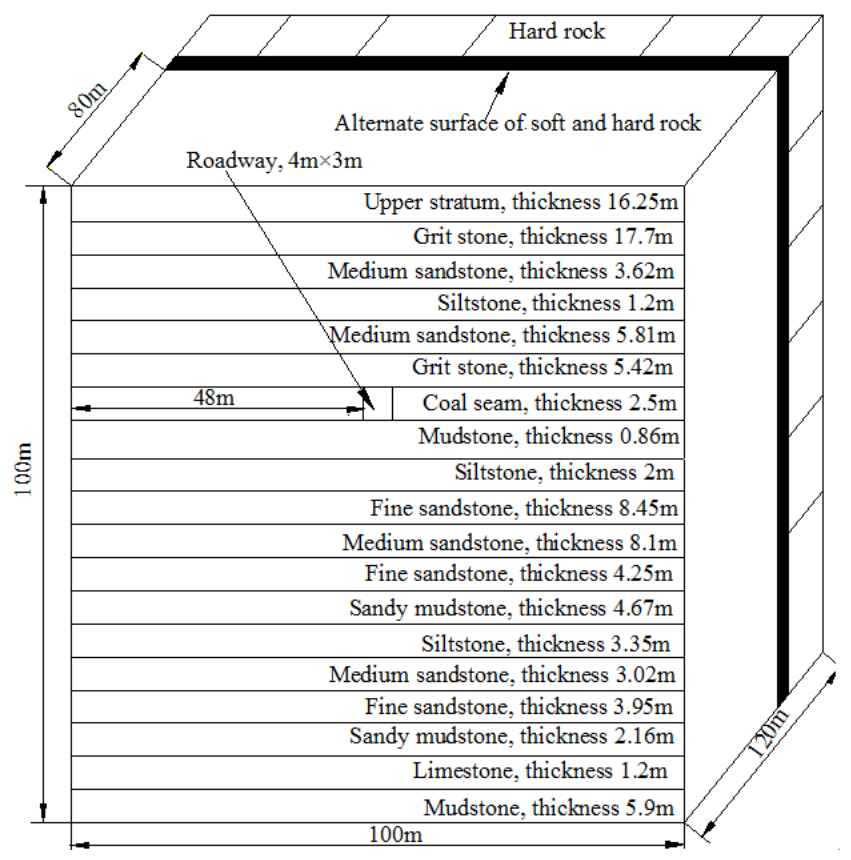

Fig. 2. Model schematic diagram of roadway crossing karst erosion area 


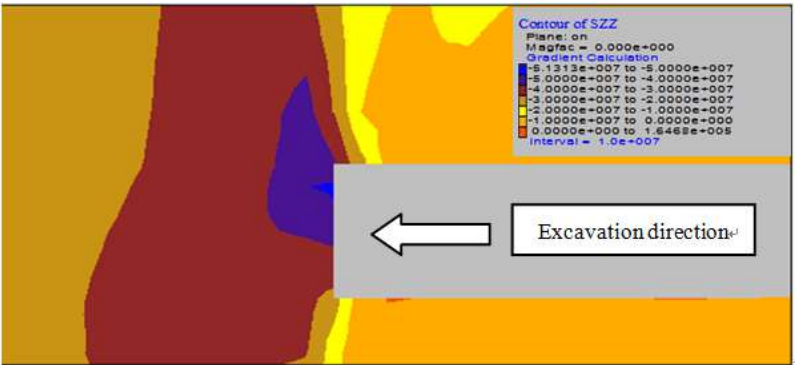

Fig. 3. Stress cloud map of crossing karst erosion area during roadway excavation

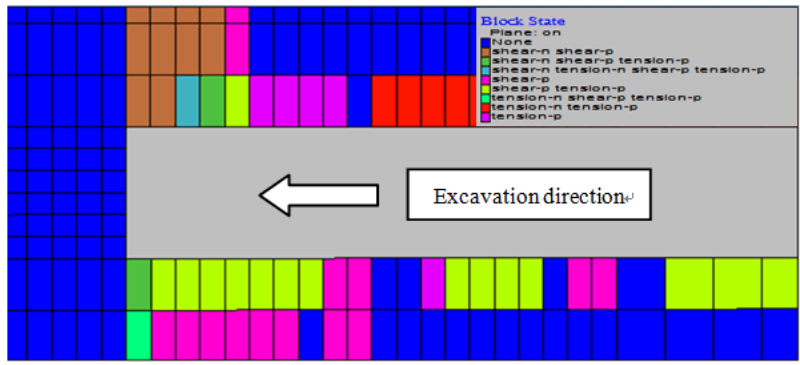

Fig. 4. Plastic zone map of crossing karst erosion area during roadway excavation

TABLE I. FORMATION PARAMETER TABLE OF RoADWAY CROSSING THE KARST AREA

\begin{tabular}{|c|c|c|c|c|c|c|}
\hline \multirow{2}{*}{ Lithology } & \multicolumn{6}{|c|}{ Formation parameters } \\
\hline & $\begin{array}{c}\text { Bulk density } \\
/(\mathbf{k g} \cdot \mathbf{m}-3)\end{array}$ & $\begin{array}{c}\text { Bulk modulus } \\
\text { /GPa }\end{array}$ & $\begin{array}{c}\text { Shear modulus } \\
\text { /GPa }\end{array}$ & $\begin{array}{c}\text { Friction angle } \\
/\left(^{\circ}\right)\end{array}$ & $\begin{array}{c}\text { Cohesion } \\
\text { /MPa }\end{array}$ & $\begin{array}{c}\text { Tensile strength } \\
\text { /MPa }\end{array}$ \\
\hline Mudstone & 2699 & 2.86 & 1.4 & 38.95 & 2.8 & 2.48 \\
\hline Limestone & 2600 & 2.0 & 1.0 & 36 & 2.5 & 2.08 \\
\hline Sandy mudstone & 2530 & 5.12 & 4.73 & 40 & 2.45 & 2.01 \\
\hline Siltstone & 2460 & 10.83 & 8.13 & 38 & 3.75 & 1.84 \\
\hline Medium sandstone & 2580 & 3.3 & 2.5 & 37 & 4.0 & 1.2 \\
\hline Fine sandstone & 2540 & 2.7 & 1.6 & 35 & 2.0 & 1.0 \\
\hline Grit stone & 2560 & 4.2 & 2.9 & 34 & 5.0 & 1.5 \\
\hline Coal seam & 1420 & 0.46 & 0.19 & 20 & 0.8 & 0.01 \\
\hline Fault & 1750 & 3.0 & 1.2 & 40 & 0.2 & 0.28 \\
\hline Hard rock & 2900 & 43.9 & 30.2 & 51 & 55.1 & 9 \\
\hline
\end{tabular}

\section{Result analysis}

As shown in Fig. 3 and Fig. 4, the stress concentration area is formed at the interface of soft and hard rock strata when the roadway exposes the karst erosion area, and the surrounding rock near the interface is seriously damaged. Magmatic rocks are dense and hard, good integrity, strong strength, and it has great load transfer ability. Because the intensity of magmatic rock is large, it is easy to produce stress concentration. The intrusion of magmatic rocks will form a high residual tectonic stress, and the hard magmatic rocks have a strong ability to contain energy, which makes the magmatic intrusive zone usually become a concentrated area of high elastic properties. During roadway excavation, it is easy to induce instantaneous release of energy in magmatic intrusion zone and form strong dynamic loading. The dynamic load is radiated in the coal and rock strata in the form of stress waves, causing disturbance to the roadways and there has the possibility of impact hazard.

\section{B. Stress distribution and failure characteristics of} surrounding rock during roadway crossing the fault

\section{Calculating model}

The model is built by FLAC ${ }^{3 \mathrm{D}}$ software. The size of the model is $500 \mathrm{~m} \times 900 \mathrm{~m} \times 100 \mathrm{~m}$, and the model is divided into nine strata. The coal seam is in the central location, with a depth of 650 meters and a thickness of 2.5 meters. The size of the roadway section is $4 \mathrm{~m} \times 2.5 \mathrm{~m}$. The size of the gob 1 is $60 \mathrm{~m} \times 575 \mathrm{~m} \times 2.5 \mathrm{~m}$, which is 95 meters distant from the roadway. The size of the gob 2 is $60 \mathrm{~m} \times 455 \mathrm{~m} \times 2.5 \mathrm{~m}$, which is 71 meters distant from the roadway. The roadway passes through the fault, and the thickness of fault is 5 meters.
The dip angle of the fault is about 75 degrees, and the distance from the initial excavation face is 803.5 meters. The model is divided into 115554 nodes and 233917 elements. As shown in Fig. 5.

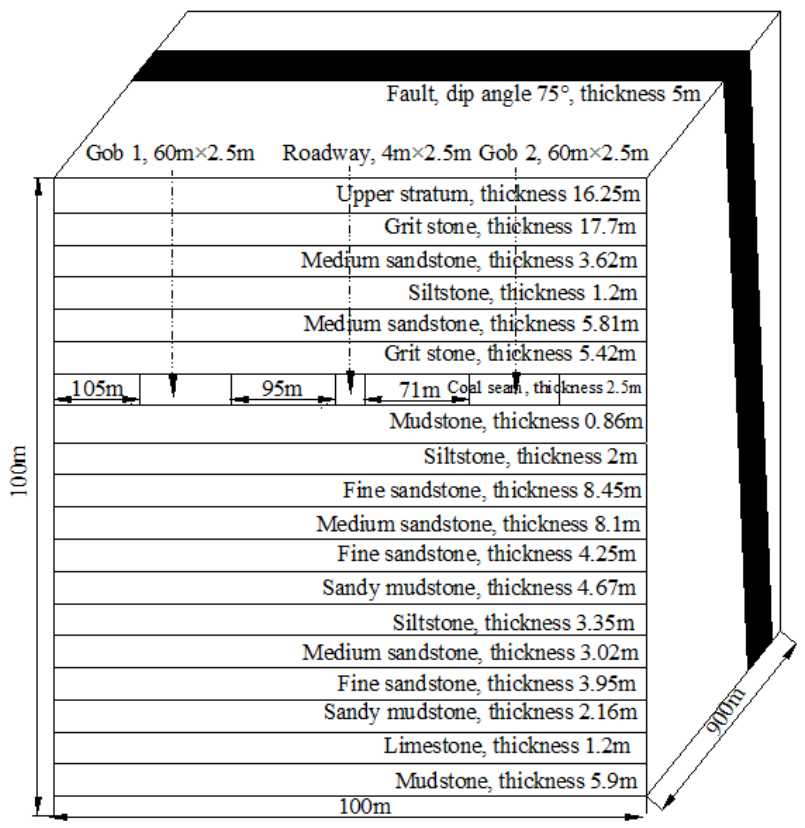

Fig. 5. Model schematic diagram of roadway crossing fault

Mohr-Coulomb model is used in this numerical simulation, and the five displacement boundaries are constrained. The pressure of 15MP is applied to the surface of the model, which is used to simulate the pressure of 600 
meters stratum. The model was divided into nine strata, and the parameters are shown in the first nine strata of Table I.

\section{Result analysis}

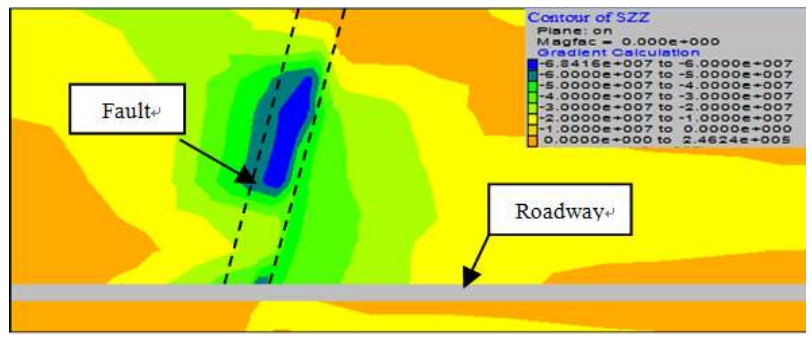

Fig. 6. Stress cloud map of crossing fault during roadway excavation

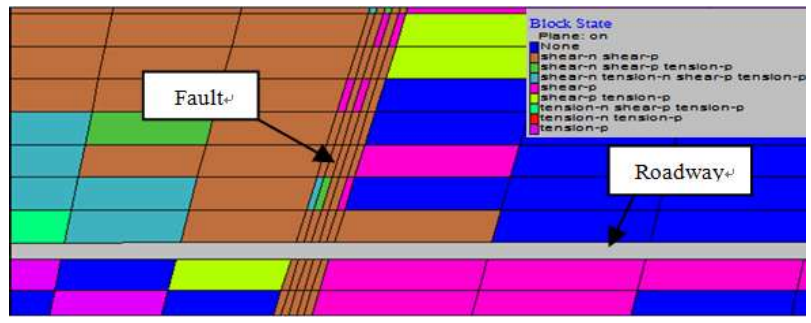

Fig. 7. Plastic zone map of crossing fault during roadway excavation

According to Fig.6 and Fig.7, when the roadway crossing the fault, the stress concentration area is formed near the fault, and the surrounding rock near the fault is seriously damaged. This is due to the instability of the fault, when the roadway crossing the fault, the residual tectonic stress on both sides of the fault is superimposed on the overbearing pressure of the coal mining face, so that the support pressure near the fault is increased and the high stress area is formed. According to the previous results, when the coal working face is pushed closer to the fault, there will form high stress difference and it is possible to have rock burst. With the increase of the drift, the NO.79 and NO.93 faults will have an influence on the roadway propulsion and coal quality, and there has the possibility of impact hazard.

In view of the important influence of fault and karst erosion area on the rockburst during roadway excavation, the geological structure, such as the fault and the karst erosion area should be considered in the impact hazard assessment. Then, the fuzzy comprehensive evaluation method is used to establish the risk evaluation system of rock burst and evaluate the impact hazard by considering geological factors and mining technical conditions.

\section{BASED ON FUZZY COMPREHENSIVE EVALUATION METHOD TO EVALUATE THE IMPACT HAZARD OF THE WEST RAIL LANE DURING ROADWAY EXCAVATION}

\section{A. The principle of fuzzy comprehensive evaluation method}

Fuzzy comprehensive evaluation method is a method which based on fuzzy mathematics. According to the membership degree theory of fuzzy mathematics, it transforms qualitative evaluation into quantitative evaluation. In other words, it uses fuzzy mathematics to make a general evaluation of objects, and these objects are restricted by many factors [22].
The basic idea of fuzzy comprehensive evaluation method is to use the degree of belonging to replace belongs or not belongs. First, the basic principle is to determine the set of evaluation factors of the evaluated object. Then the weight and membership vector of each factor are determined, and the fuzzy evaluation matrix is obtained. Finally, the fuzzy evaluation matrix and the weight vector of the factors are fuzzed and normalized, and the fuzzy comprehensive evaluation results are obtained. The fuzzy comprehensive evaluation method has the characteristics of clear results and strong systematicness. It is suitable to solve all kinds of non deterministic problems.

\section{B. Fuzzy comprehensive evaluation of impact hazard in west track lane}

\section{Selection of evaluation index}

There are many factors affecting the danger of roadway dynamic disasters, in addition to the impact tendency, the influence factors of geology are: mining depth, physical and mechanical properties of coal seam, roof rock structure, geological structure, etc. Technical factors include: gob, driving way, driving speed, coal pillar retaining, supporting method, roadway level, etc. First of all, the influence factors of geological conditions and technical conditions on rock burst are determined. Then, the influence index of each factor on rock burst is analyzed, and the fuzzy evaluation model of impact hazard state is established. In this paper, indexes are divided into two categories, one is geological factor, it mainly includes the geological conditions and the occurrence of coal seam. The other is driving technology factor, which is mainly composed of technical conditions in coal working face excavation. In summary, the risk evaluation index system for rock burst in coal mining face is shown in Table II.

TABLE II. EVALUATION INDEX OF IMPACT HAZARD IN WEST RAIL LANE

\begin{tabular}{|c|c|}
\hline Geological factors & Technical factors \\
\hline Mining depth & Coal pillar size \\
\hline Impact orientation of coal seam & Driving method \\
\hline Impact orientation of roof & Driving speed \\
\hline Rock stratum structure & Mutual interference in mining \\
\hline The degree of structural stress & Support mode \\
\hline $\begin{array}{c}\text { Influence degree of fault and } \\
\text { broken zone }\end{array}$ & \\
\hline $\begin{array}{c}\text { Change of thickness and dip angle } \\
\text { of coal seam }\end{array}$ & \\
\hline Dip angle of coal seam & \\
\hline
\end{tabular}

The determination of the membership function and the fuzzy matrix

According to the characteristics of rock burst, the impact hazard status is divided into four grades, that is, grade I, II, III and IV, which represent four cases of no impact, weak impact, medium impact and strong impact. Then, the membership degree of the evaluation index is calculated, and the evaluation indexes of the impact hazard are classified and made into a single factor index, as shown in Table III.

For some indicators in the table, they can't be quantified, so qualitative division is carried out. For example, mining interference is divided into four categories: weak, general, stronger and strong. 
TABLE III. EvaluATION INDEX ClassificATION OF Rock BURST

\begin{tabular}{|c|c|c|c|c|c|}
\hline \multirow{2}{*}{ Factor } & \multicolumn{5}{|c|}{ Impact hazard indicators and classification } \\
\hline & Indicators & $\mathrm{I}$ & II & III & IV \\
\hline \multirow{9}{*}{$\begin{array}{l}\text { Geological } \\
\text { factors }\end{array}$} & Frequency of rock burst & 0 & $\mathrm{n} \leq 1$ & $\mathrm{n} \leq 2$ & $\mathrm{n} \geq 3$ \\
\hline & Mining depth & $\leq 400 \mathrm{~m}$ & $\leq 600 \mathrm{~m}$ & $\leq 800 \mathrm{~m}$ & $>800 \mathrm{~m}$ \\
\hline & $\begin{array}{l}\text { Impact orientation of } \\
\text { coal seam }\end{array}$ & No impact & Weak impact & Medium impact & Strong impact \\
\hline & $\begin{array}{l}\text { Impact orientation of } \\
\text { roof }\end{array}$ & No impact & Weak impact & Medium impact & Strong impact \\
\hline & $\begin{array}{l}\text { Distance between hard } \\
\text { roof and coal seam }\end{array}$ & $>100 \mathrm{~m}$ & $\leq 100 \mathrm{~m}$ & $\leq 50 \mathrm{~m}$ & $<20 \mathrm{~m}$ \\
\hline & Tectonic stress & low & General & Upper & High \\
\hline & $\begin{array}{l}\text { Influence degree of } \\
\text { fault and broken zone }\end{array}$ & low & General & Upper & High \\
\hline & $\begin{array}{l}\text { Change of thickness } \\
\text { and dip angle of coal } \\
\text { seam }\end{array}$ & Stable coal seam & Stably coal seam & Unstable coal seam & $\begin{array}{l}\text { Extremely unstable coal } \\
\text { seam }\end{array}$ \\
\hline & Dip angle of coal seam & $\leq 10^{\circ}$ & $\leq 35^{\circ}$ & $\leq 60^{\circ}$ & $>60^{\circ}$ \\
\hline \multirow{6}{*}{ Technical factors } & Coal pillar size & $<5 \mathrm{~m}$ or $>50 \mathrm{~m}$ & $5-10 \mathrm{~m}$ & $10-15 \mathrm{~m}$ & $15-50 \mathrm{~m}$ \\
\hline & Mining method & - & $\begin{array}{l}\text { Fully mechanized } \\
\text { mining }\end{array}$ & Blasting driving & - \\
\hline & Roof weighting display & Not obvious & obvious & strong & Very strong \\
\hline & Mining speed & $\leq 4 \mathrm{~m} / \mathrm{d}$ & $\leq 8 \mathrm{~m} / \mathrm{d}$ & $\leq 10 \mathrm{~m} / \mathrm{d}$ & $>10 \mathrm{~m} / \mathrm{d}$ \\
\hline & Layer of roadway & Rock roadway & $\begin{array}{l}\text { Coal top rock } \\
\text { bottom }\end{array}$ & Rock top coal bottom & Coal top coal bottom \\
\hline & $\begin{array}{l}\text { Mutual interference in } \\
\text { mining }\end{array}$ & weak & General & Stronger & strong \\
\hline
\end{tabular}

TABLE IV. Membership Function Table For Evaluation Factors In West Rail Lane

\begin{tabular}{|c|c|c|c|c|}
\hline \multirow{2}{*}{$\begin{array}{c}\text { Evaluating } \\
\text { indicator }\end{array}$} & \multicolumn{4}{|c|}{ Impact hazard classification } \\
\hline & I & II & III & IV \\
\hline Mining depth & $\begin{array}{ll}1, & x \leq 400 \\
\frac{600-x}{600-400}, & 400<x<600 \\
0, & x \geq 600\end{array}$ & $\begin{cases}\frac{x-400}{600-400}, & 400<x \leq 600 \\
\frac{800-x}{800-600}, & 600<x<800 \\
0, & x \leq 400, x>800\end{cases}$ & $\begin{array}{ll}\frac{x-600}{800-600}, & 600<x \leq 800 \\
0, & x>800\end{array}$ & $\left\{\begin{array}{l}0, x \leq 800 \\
1, x>800\end{array}\right.$ \\
\hline $\begin{array}{l}\text { Distance } \\
\text { between } \\
\text { hard-thick } \\
\text { roof and coal } \\
\text { seam }\end{array}$ & $\begin{array}{l}1, \quad x \geq 100 \\
0, \quad x<100\end{array}$ & $\begin{cases}\frac{x-50}{100-50}, & 50<x<100 \\
0, & x \geq 100\end{cases}$ & $\begin{cases}\frac{x-20}{50-20}, & 20<x \leq 50 \\
\frac{100-x}{100-50}, & 50<x<100 \\
0, & x<20, x \geq 100\end{cases}$ & $\begin{cases}1, & x<20 \\
\frac{50-x}{50-20}, & 20 \leq x<50 \\
0, & x \geq 50\end{cases}$ \\
\hline $\begin{array}{l}\text { Dip angle } \\
\text { of coal seam }\end{array}$ & $\begin{array}{ll}1, & x \leq 10 \\
\frac{35-x}{35-10}, & 10<x<35 \\
0, & x \geq 35\end{array}$ & $\begin{cases}\frac{x-10}{35-10}, & 10<x \leq 35 \\
\frac{60-x}{60-35}, & 35<x<60 \\
0, & x \leq 10, x>60\end{cases}$ & $\begin{cases}\frac{x-35}{60-35}, & 35<x \leq 60 \\
0, & x>60\end{cases}$ & $\begin{cases}0, & x \leq 60 \\
1, & x>60\end{cases}$ \\
\hline Mining speed & $\begin{array}{ll}1, & x \leq 4 \\
\frac{8-x}{8-4}, & 4<x<8 \\
0, & x \geq 8\end{array}$ & $\begin{cases}\frac{x-4}{8-4}, & 4<x \leq 8 \\
\frac{10-x}{10-8}, & 8<x<10 \\
0, & x \leq 4, x>10\end{cases}$ & $\begin{cases}\frac{x-8}{10-8}, & 8<x \leq 10 \\
0, & x>10\end{cases}$ & $\begin{cases}0, & x \leq 10 \\
1, & x>10\end{cases}$ \\
\hline
\end{tabular}


After determining the grading standards, the fuzzy sets of the evaluation indicators are determined according to the different characteristics and actual conditions of each evaluation index. For indicators with higher index values and higher risk of impact, reverse the order of the ranks of the original membership functions, and then calculate. The membership function of trapezoid distribution or half trapezoid distribution was selected to segment different intervals. In this way, each grade has a different membership function. Its structure is shown in Fig. 8, the abscissa is the index value, and $\mathrm{x}$ is the threshold of different levels, $\mathrm{a}$ and $\mathrm{b}$ are the corresponding intermediate values, and the ordinates are the membership values. The expression is as follows.
(1) Mini type (Fig. 8a)
(2) Large type(Fig. 8b)
(3) Intermediate type (Fig. 8c)

$$
\left\{\begin{array} { l l } 
{ 1 } & { \mathrm { x } < 4 0 0 } \\
{ \frac { \mathrm { b } - \mathrm { x } } { \mathrm { b } - \mathrm { a } } , } & { \mathrm { a } \leq \mathrm { x } \leq \mathrm { b } } \\
{ 0 } & { \mathrm { b } < \mathrm { x } }
\end{array} \left\{\begin{array} { l l } 
{ 0 } & { \mathrm { x } < \mathrm { a } } \\
{ \frac { \mathrm { x } - \mathrm { a } } { \mathrm { b } - \mathrm { a } } , } & { \mathrm { a } \leq \mathrm { x } \leq \mathrm { b } } \\
{ 1 } & { \mathrm { b } < \mathrm { x } }
\end{array} \left\{\begin{array}{ll}
\frac{\mathrm{x}-\mathrm{a}}{\mathrm{b}-\mathrm{a}}, & \mathrm{a} \leq \mathrm{x}<\mathrm{b} \\
1, & \mathrm{~b} \leq \mathrm{x}<\mathrm{c} \\
\frac{\mathrm{d}-\mathrm{x}}{\mathrm{d}-\mathrm{c}}, & \mathrm{c} \leq \mathrm{x} \leq \mathrm{d}
\end{array}\right.\right.\right.
$$
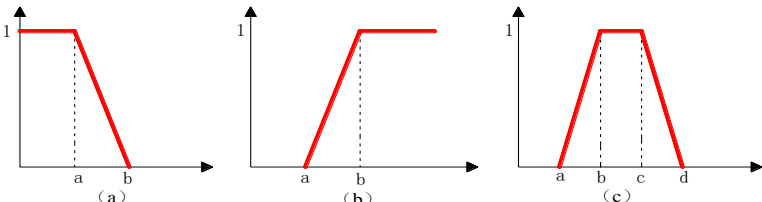

Fig. 8. Trapezoid and semi trapezoid fuzzy distribution

The expression of membership function for impact hazard is shown in Table IV.

For qualitative indicators, the membership degree is 1 , and the membership degree of other levels is 0 . According to the actual situation of the mining area, combining with tables III and IV, the membership of each evaluation index of the west rail lane can be calculated as shown in Table $\mathrm{V}$.

TABLE V. MEMBERShIP List Of Evaluation Factors In The West RAIL LANE

\begin{tabular}{|c|c|c|c|c|c|}
\hline \multirow{2}{*}{ Evaluating indicator } & \multirow{2}{*}{$\begin{array}{l}\text { Working conditions of } \\
\text { mining area and west rail } \\
\text { lane }\end{array}$} & \multicolumn{4}{|c|}{ Classify membership degree of impact hazard } \\
\hline & & $\mathrm{I}$ & II & III & IV \\
\hline Frequency of rock burst & 0 & 1 & 0 & 0 & 0 \\
\hline Mining depth & 693 & 0 & 0.535 & 0.465 & 0 \\
\hline Impact orientation of coal seam & Weak & 0 & 1 & 0 & 0 \\
\hline Impact orientation of roof & Weak & 0 & 1 & 0 & 0 \\
\hline $\begin{array}{l}\text { Distance between hard-thick roof } \\
\text { and coal seam }\end{array}$ & $>100 \mathrm{~m}$ & 1 & 0 & 0 & 0 \\
\hline Tectonic stress (Fault or folds) & Low & 1 & 0 & 0 & 0 \\
\hline $\begin{array}{l}\text { Influence degree of fault and } \\
\text { broken zone }\end{array}$ & Low & 1 & 0 & 0 & 0 \\
\hline $\begin{array}{l}\text { Change of thickness and dip angle } \\
\text { of coal seam }\end{array}$ & Stably coal seam & 0 & 1 & 0 & 0 \\
\hline Dip angle of coal seam & $8^{\circ}$ & 1 & 0 & 0 & 0 \\
\hline Coal pillar size & $>50 \mathrm{~m}$ & 1 & 0 & 0 & 0 \\
\hline Roof weighting display & Not obvious & 1 & 0 & 0 & 0 \\
\hline Mining speed & $4 \mathrm{~m} / \mathrm{d}$ & 1 & 0 & 0 & 0 \\
\hline Layer of roadway & Rock roadway & 1 & 0 & 0 & 0 \\
\hline Mutual interference in mining & Weak & 1 & 0 & 0 & 0 \\
\hline
\end{tabular}

From table V, we can get a $14 \times 4$ fuzzy matrix, which is written in R:

$$
R=\left[\begin{array}{cccc}
1 & 0 & 0 & 0 \\
0 & 0.535 & 0.465 & 0 \\
0 & 1 & 0 & 0 \\
0 & 1 & 0 & 0 \\
1 & 0 & 0 & 0 \\
1 & 0 & 0 & 0 \\
1 & 0 & 0 & 0 \\
0 & 1 & 0 & 0 \\
1 & 0 & 0 & 0 \\
1 & 0 & 0 & 0 \\
1 & 0 & 0 & 0 \\
1 & 0 & 0 & 0 \\
1 & 0 & 0 & 0 \\
1 & 0 & 0 & 0
\end{array}\right]
$$

\section{Determine the weight of each index}

The weight can be determined by considering the exceeding standard of the impact hazard index. The more exceeding the standard, the greater influence on the impact hazard, also the weight is bigger.

$$
W_{i}=c_{i} / \overline{c_{0 i}}
$$

In (2), $C_{i}$ is the actual value of the NO. i index in the mining area.

$\overline{c_{0 i}}$ is the average value of the standard limit values for the impact level of the NO. i indicator at each level. 
Because the weight of a single index is not related to a certain level of single grading standards, for $\overline{c_{0 i}}$, if a single index is divided into four levels, their average value is taken:

$$
\overline{c_{0 i}}=\frac{1}{4}\left(I_{i}+I I_{i}+I I I_{i}+I V_{i}+V_{i}\right)
$$

For example, the weight of the mining depth is:

$$
W_{i}=\frac{C_{1}}{C_{01}}
$$

In (4), $\boldsymbol{C}_{1}$ is the measured value. $C_{01}$ is the average value of the standard values of four levels, it is calculated by (3).

The weight of each index calculated by the above weighting formula is a relative weight. In order to make it easier to compare, it is necessary to normalize the weight, and the sum of the weights of the indicators should be equal to 1 . Equation (5) can be used to calculate the weight. That is:

$$
W_{i}=\frac{W_{i}}{\sum_{i=1}^{n} W_{i}} \quad(\mathrm{i}=1,2, \ldots, \mathrm{n})
$$

In this case, the set of $U$ consists of 14 indexes, so it needs to form a $1 \times 14$ order weight matrix. It is also a fuzzy matrix, known as A. In combination with Physical properties testing and impact orientation identification of No. 3 coal seam, the weights of various indexes can be calculated by the

\begin{tabular}{|c|c|c|c|c|c|c|c|c|c|c|c|c|c|c|}
\hline \multirow[b]{2}{*}{ variable } & \multicolumn{14}{|c|}{ Engineering geological conditions } \\
\hline & \begin{tabular}{|c|} 
Frequency \\
of \\
rockburst
\end{tabular} & $\begin{array}{c}\text { Mining } \\
\text { depth }\end{array}$ & \begin{tabular}{|c|} 
Impact \\
orientation \\
of coal \\
seam
\end{tabular} & \begin{tabular}{|c|} 
Impact \\
orientation \\
of roof
\end{tabular} & \begin{tabular}{|c|} 
Distance \\
between \\
hard-thick \\
roof and \\
coal seam
\end{tabular} & \begin{tabular}{|c|} 
Tectonic \\
stress \\
(Fault or \\
folds)
\end{tabular} & \begin{tabular}{|c|} 
Influence \\
degree of \\
fault and \\
broken \\
zone
\end{tabular} & \begin{tabular}{|c|} 
Change of \\
thickness \\
and dip \\
angle of \\
coal seam
\end{tabular} & \begin{tabular}{|c} 
Dip \\
angle of \\
coal \\
seam
\end{tabular} & $\begin{array}{c}\text { Coal } \\
\text { pillar } \\
\text { size }\end{array}$ & \begin{tabular}{|c|} 
Roof \\
weighting \\
display
\end{tabular} & $\begin{array}{c}\text { Mining } \\
\text { speed }\end{array}$ & $\begin{array}{l}\text { Layer of } \\
\text { roadway }\end{array}$ & $\begin{array}{c}\text { Mutual } \\
\text { interference } \\
\text { in mining }\end{array}$ \\
\hline$C_{i}$ & 0 & 693 & 75.8 & 50.59 & 100 & ---- & ---- & ---- & 8 & 60 & ---- & 4 & ---- & ---- \\
\hline$C_{0 i}$ & 6 & 650 & 119.3 & 70 & 67.5 & --- & ---- & ---- & 41.25 & 31.25 & ---- & 8 & ---- & ---- \\
\hline$W_{i}$ & 0 & 1.07 & 0.64 & 0.72 & 1.48 & ---- & ---- & ---- & 0.19 & 1.92 & --- & 0.5 & ---- & --- \\
\hline $\begin{array}{l}W_{i}= \\
W_{i} / \Sigma W_{i}\end{array}$ & 0 & 0.16 & 0.098 & 0.11 & 0.23 & ---- & ---- & ---- & 0.029 & 0.29 & ---- & 0.077 & ---- & ---- \\
\hline
\end{tabular}
above expressions, as shown in Table VI.

TABLE VI. WeIGHT CALCULATION TABLE For EACH EVALUATION INDEX

In Table VI,

$\sum W_{i}=0+1.07+0.64+0.72+1.48+0.19+1.92+0.5=6.52$

From table VI, the weight fuzzy matrix $\mathrm{A}$ is:

$A=(0,0.16,0.098,0.11,0.23,0.029,0.29,0.077)$

\section{Impact hazard level assessment}

Combined with table VI, the modified fuzzy matrix is:

$$
R^{\prime}=\left[\begin{array}{cccc}
1 & 0 & 0 & 0 \\
0 & 0.535 & 0.465 & 0 \\
0 & 1 & 0 & 0 \\
0 & 1 & 0 & 0 \\
1 & 0 & 0 & 0 \\
1 & 0 & 0 & 0 \\
1 & 0 & 0 & 0 \\
1 & 0 & 0 & 0
\end{array}\right]
$$

We can use the appropriate operator to synthesize the $U$ and the $\mathrm{R}$ of the evaluated objects, the fuzzy comprehensive evaluation result vector $B$ of each evaluated item can be obtained. Vector B is:

$\left.B=A \circ R^{\prime}=(0,0.16,0.098,0.11,0.23,0.029,0.29,0.077)\right)\left|\begin{array}{cccc}1 & 0 & 0 & 0 \\ 0 & 0.535 & 0.465 & 0 \\ 0 & 1 & 0 & 0 \\ 0 & 1 & 0 & 0 \\ 1 & 0 & 0 & 0 \\ 1 & 0 & 0 & 0 \\ 1 & 0 & 0 & 0 \\ 1 & 0 & 0 & 0\end{array}\right|$

The fuzzy composite operator is based on the following algorithm

$$
b_{j}=\underset{i=1}{v}\left(a_{i} \wedge r_{i j}\right)=\max _{1 \leq i \leq m}\left|\min \left(a_{i}, r_{i j}\right)\right|, j=1,2, \cdots, n
$$

So

$$
B=0.29,0.16,0.16,0
$$

After normalization: (Note: the total amount is 0.61 )

$$
B=0.48,0.26,0.26,0
$$

The upper formula shows that the membership grade of the impact hazard is $0.48,0.26,0.26,0$, which belongs to the danger degree of I to IV. According to the principle of maximum membership, if the result of fuzzy comprehensive evaluation is: 


$$
\exists b_{r}=\max _{1 \leq j \leq n} b_{j}
$$

The evaluated object belongs to level R. Therefore, the impact hazard level in the west rail lane is I, and there is no impact hazard.

\section{EARLY-WARNING MONITORING OF ROCK BURST}

We used the drilling cuttings method to monitor rock burst in the mining area, where is not affected by the advanced supporting pressure. The diameter of the drill hole is $42 \mathrm{~mm}$, and the depth is $12 \mathrm{~m}$. The drill hole is arranged at $1.2 \mathrm{~m}$ from the floor of the coal seam. The inclination of drill hole is consistent with the dip angle of coal seam, and the drill hole spacing is $10 \mathrm{~m}$. Six drill holes were arranged, of which 3 holes are arranged on the upper part, numbered 1 to $3 \#$, and the other 3 holes are arranged in the lower part, numbered 3 to $6 \#$. During the drilling, the whole process is smoothly. There is no shock sound, drill rod beating, drill rod failure and other phenomena, which indicating that the stress state of coal body near the drill hole is good. The layout of the drill hole during the west rail lane excavation is shown in Fig. 9.

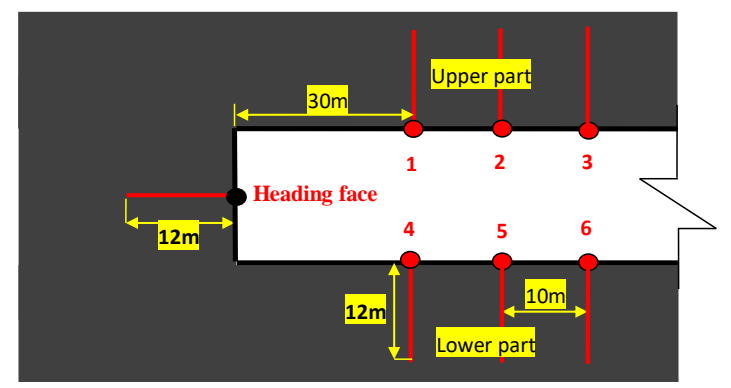

Fig. 9. The layout of the drill hole

The measured value of coal powder amount is shown in Fig. 10. According to the analysis of drilling powder amount, the amount of powder in deep drilling is on the increase trend, and the main reason is that the stress in the deep coal body is high. According to The research report on using drilling cuttings method to monitor the impact hazard in mining area, the critical index of powder amount is listed in Table VII. The drilling position is not affected by the geological structure and the front support pressure of coal mining face, and compared the actual amount of drilling powder and the critical index, there is no impact hazard. The amount of coal powder obtained from monitoring drill hole can be regarded as normal coal powder amount.

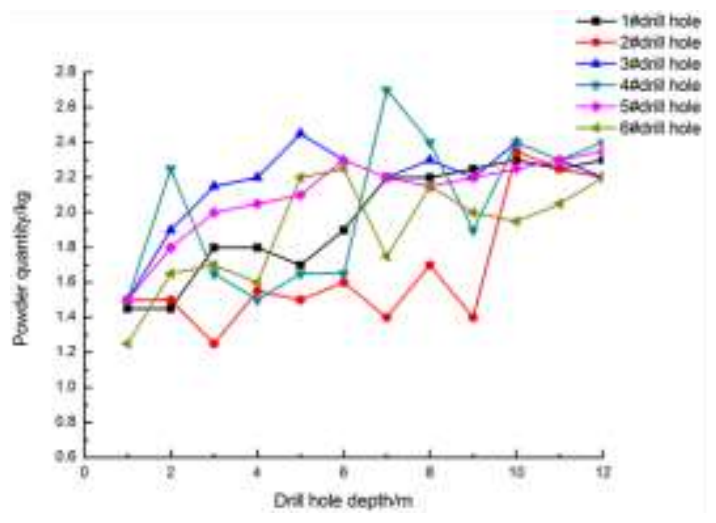

Fig. 10. Analysis of measured value of drilling amount
TABLE VII. DRILLING COAL POWDER AMOUNT CRITICAL INDEX

\begin{tabular}{|l|c|c|c|}
\hline $\begin{array}{l}\text { Drill hole depth/ Thickness of } \\
\text { coal seam }\end{array}$ & 1.5 & $1.5 \sim 3$ & 3 \\
\hline Powder rate index & $>1.5$ & $2 \sim 3$ & $\geq 4$ \\
\hline Drill hole depth $/ \mathrm{m}$ & $1 \sim 4$ & $5 \sim 7$ & $8 \sim 12$ \\
\hline Critical value index $/ \mathrm{kg}$ & 2.52 & $3.8 \sim 5.82$ & 8.64 \\
\hline
\end{tabular}

According to the engineering practice, the four mining areas have not experienced rock burst in the finished working face. According to the results of various indexes and engineering experience, it is found that there is no impact hazard in the west rail lane, which is consistent with the conclusion of the fuzzy comprehensive evaluation method. The fuzzy comprehensive evaluation method has important guiding significance for the analysis of the impact hazard in the roadway excavation process.

\section{CONCLUSIONS}

In this paper, the fuzzy comprehensive evaluation method is used to evaluate the impact hazard of roadway excavation in fault and karst erosion area. FLAC3D numerical simulation is used to analyze the influence of fault and karst erosion areas on roadway excavation. Then, the evaluation index system of rock burst is constructed, and the results are compared with the monitoring results. The main conclusions are as follows:

(1) With the analysis of numerical simulation, the stress concentration area is formed near the fault and karst erosion area when the roadway crossing the fault and the karst erosion area, and the surrounding rock is seriously damaged. The excavation of the roadway induces the instantaneous release of energy in the stress concentration area and forms strong dynamic loading. The dynamic load is radiated in the coal and rock strata in the form of stress waves, causing disturbance to the roadways and this region may have the possibility of inducing rock burst. Therefore, the impact of these two conditions on rock burst should be taken into account in the evaluation of rock burst.

(2) The results of fuzzy comprehensive evaluation show that there is no impact hazard during the roadway excavation, which is consistent with the monitoring results of drilling cuttings method. It is proved that the fuzzy comprehensive evaluation method is effective in evaluating the impact hazard during roadway excavation. The fuzzy comprehensive evaluation method is convenient and scientific, and the result of the evaluation is consistent with the field demonstration. It provides a new method for the evaluation of the impact hazard in coal mine.

(3) The fuzzy comprehensive evaluation method has strong subjectivity to determine the weight of the index. In the future evaluation research, it is necessary to study how to reduce the subjectivity of the evaluation method, making the fuzzy comprehensive evaluation method more scientific and reasonable to evaluate the impact hazard of coal mine. 


\section{ACKNOWLEDGMENT}

In this paper, the research was sponsored by the National Natural Science Foundation of China (Grant No. 51774196), China Postdoctoral Science Foundation(No.2016M592221), and SDUST Young Teachers Teaching Talent Training Plan (No. BJRC20160501).

\section{REFERENCES}

[1] W. D. Ortlepp and T. R. Stacey, "Rockburst mechanisms in tunnels and shafts,” Tunn. Undergr. Sp. Tech, vol. 9, pp. 59-65, 1994

[2] Łukasz Wojtecki and P. Konicek, "Estimation of active rockburs prevention effectiveness during longwall mining under disadvantageous geological and mining conditions," J. Sustain. Min, vol. 15 , pp. 1-7, 2016

[3] T. H. Ma, C. A. Tang, L. X. Tang, W. D. Zhang, and L. Wang, "Mechanism of rock burst forcasting based on micro-seismic monitoring technology," Chin. J. Rock. Mech. Eng, vol. 3, pp. 470483, 2016.

[4] N. G. W. Cook, E. Hoek, J. P. G. Pretorius, W. D. Ortlepp, and M. D. G. Salamon, "Rock mechanics applied to the study of rockbursts," J. S. Afr. I. Min. Metall, Vol. 66, pp. 435-528, 1966.

[5] C. Mark, "Coal bursts that occur during development: A rock mechanics enigma,” Int. J. Min. Sci. Tech, vol. 28, pp. 35-42, 2018.

6] R. Singh, A. Kumar, R. Kumar, A. K. Singh, and A. K. Singh, "Underground mining of deep seated thick coal seams: An analysis from rock mechanics prospective," NexGen. Tech. Min. Fuel. Ind, 2017

[7] Z. H. Zhao, W. M. Wang, C. Q. Dai, and J. X. Yan, "Failure characteristics of three-body model composed of rock and coal with different strength and stiffness," T. Nonferr. Metal. Soc, vol. 24, pp. $1538-1546,2014$

[8] D. W. Yin, S. J. Chen, X. Q. Liu , and H. F. Ma, "Effect of joint angle in coal on failure mechanical behavior of rock-coal combined body," Q. J. Eng. Geol. Hydroge, vol. 51, pp. 202-209, 2018.

[9] S. J. Chen, D. W. Yin, B. L. Zhang, H. F. Ma, and X. Q. Liu, "Study on mechanical characteristics and progressive failure mechanism of roof-coal pillar structure body,” Chin J. Rock Mech. Eng, vol. 36, pp. $1588-1598,2017$.

[10] X. Q. Wu, "Evaluation and prevention of bumping danger from full seam mining in unstable thick seam," J. Coal. Sci. Tech, vol. 38, pp. $22-27,2010$
[11] Z. Y. Song, H. G. Ji, and L. H. Sun, "Research progress on impact tendency index test of coal and rock," Chin. J. Undergr. Sp. Eng, vol. 11, pp. 401-407, 2015.

[12] H. W. Zhang, H. Rong, J. Q. Chen, et al. "Risk assessment of rockburst based on geo-dynamic division method in suberect and extremely thick coal seam," J. China. Coal. Soc, vol. 40, pp. 2755$2762,2015$.

[13] H. Rong, H. W. Zhang, J. Q. Chen, et al. "Risk prediction of rockburst in steep and extra thick coal seam based on multi factor pattern recognition,” J. Min. Safety. Eng, pp. 125-132, 2018

[14] D. Wei, J. Wesseloo, and Y. Potvin. "Evaluation of the adjusted rockburst damage potential method for dynamic ground support selection in extreme rockburst conditions," Proc. Inte. Semi. Desi. Methods. Undergr. Min. Australian Centre for Geomechanics, Perth, pp. 399-418.

[15] G. L. Feng, X. T. Feng, B. R. Chen, Y. X. Xiao, and Y. Yu, "A Microseismic Method for Dynamic Warning of Rockburst Development Processes in Tunnels," Rock. Mech. Rock. Eng, vol. 48, pp. 2061-2076, 2015.

[16] J. Kornowski and J. Kurzeja, "Prediction of rockburst probability given seismic energy and factors defined by the expert method of hazard evaluation (MRG)," Acta. Geophy, vol. 60, pp. 472-486, 2012.

[17] L. Z. Song, T. X. Wang, Y. He, W. J. Liu, and W. B. Fang, "Risk assessment of semi isolated island working face based on possibility index method," Safety. Coal. Mines, vol. 46, pp. 209-211, 2015.

[18] J. C. V. Lenteren, A. J. M. Loomans, F. Bigler, D. Babendreier, and U. Kuhlmann, "Environmental risk assessment: methods for comprehensive evaluation and quick scan," Environmental Impact of Invertebrates for Biological Control of Arthropods: Methods and Risk Assessment. pp. 254-272, 2006.

[19] T. A. Sondergeld and K. L. K. Koskey, "Evaluating the impact of an urban comprehensive school reform: An illustration of the need for mixed methods," Stud. Edu. Eval, vol. 37, pp. 94-107, 2011.

[20] G. Y. Wang and J. Liu, "Fuzzy matter-element evaluation method for analysis of surrounding rock stability," J. Hydra. Eng, vol. 35, pp. 0020-0024, 2004

[21] C. L. Wang, A. X. Wu, H. Lu, T. C. Bao, X. H. Liu, "Predicting rock burst tendency based on fuzzy matter-element model," Int. J. Rock. Mech. Min. Sci, vol. 75, pp. 224-232, 2015.

[22] W. X. Li, "Fuzzy mathematical method in rock mechanics," Acta. Mech. Sinica, vol. 6, pp. 328-336,1990.

[23] 